\title{
The Relationship of Area-Level Sociodemographic Characteristics, Household Composition and Individual-Level Socioeconomic Status on Walking Behavior Among Adults
}

\section{Citation}

Hearst, Mary O., John R. Sirard, Ann Forsyth, Emily D. Parker, Elizabeth G. Klein, Christine G. Green, and Leslie A. Lytle. 2013. The Relationship of Area-Level Sociodemographic Characteristics, Household Composition and Individual-Level Socioeconomic Status on Walking Behavior Among Adults. Transportation Research Part A: Policy and Practice 50: 149-157.

\section{Published Version}

doi:10.1016/j.tra.2013.01.006

\section{Permanent link}

http://nrs.harvard.edu/urn-3:HUL.InstRepos:12813172

\section{Terms of Use}

This article was downloaded from Harvard University's DASH repository, and is made available under the terms and conditions applicable to Open Access Policy Articles, as set forth at http:// nrs.harvard.edu/urn-3:HUL.InstRepos:dash.current.terms-of-use\#OAP

\section{Share Your Story}

The Harvard community has made this article openly available.

Please share how this access benefits you. Submit a story.

Accessibility 


\title{
The relationship of area-level sociodemographic characteristics, household composition and individual-level socioeconomic status on walking behavior among adults
}

\author{
Mary O. Hearst ${ }^{a}$, John R. Sirard ${ }^{b}$, Ann Forsyth ${ }^{c}$, Emily D. Parker ${ }^{d}$, Elizabeth G. Klein ${ }^{\mathrm{e}}$, \\ Christine G. Green ${ }^{f}$, and Leslie A. Lytle ${ }^{g}$ \\ aSt. Catherine University, 2004 Randolph Avenue, Saint Paul, MN 55105 mohearst@stkate.edu \\ bKinesiology Program, Curry School of Education, University of Virginia, Memorial Gymnasium, \\ Room 223A, Charlottesville, VA 22904 jrs2wg@virginia.edu \\ 'Urban Planning and Design, Harvard University, 48 Quincy Street, Cambridge, MA 02138, USA \\ aforsyth@gsd.harvard.edu \\ dHealthPartners Research Foundation, Minneapolis, MN Emily.d.parker@healthpartners.com \\ eCollege of Public Health, Ohio State University, 174 W. $18^{\text {th }}$ Avenue, 3138B Smith Lab, \\ Columbus, OH 43210, USA klein.232@osu.edu \\ fColumbus Public Health, 240 Parsons Avenue, Columbus, OH 43215 CGGreen@columbus.gov \\ gUNC Gillings School of Global Public Health, University of North Carolina, Chapel Hill, NC 27599 \\ Ilytle@email.unc.edu
}

\begin{abstract}
Understanding the contextual factors associated with why adults walk is important for those interested in increasing walking as a mode of transportation and leisure. This paper investigates the relationships between neighborhood-level sociodemographic context, individual level sociodemographic characteristics and walking for leisure and transport. Data from two community-based studies of adults $(n=550)$ were used to determine the association between the area-sociodemographic environment (ASDE), calculated from U.S. Census variables, and individual-level SES as potential correlates of walking behavior. Descriptive statistics, mean comparisons and Pearson's correlations coefficients were used to assess bivariate relationships. Generalized estimating equations were used to model the relationship between ASDE, as quartiles, and walking behavior. Adjusted models suggest adults engage in more minutes of walking for transportation and less walking for leisure in the most disadvantaged compared to the least disadvantaged neighborhoods but adding individual level demographics and SES eliminated the significant results. However, when models were stratified for free or reduced cost lunch, of those with children who qualified for free or reduced lunch, those who lived in the wealthiest neighborhoods engaged in 10.7 minutes less of total walking per day compared to those living in the most challenged neighborhoods $(\mathrm{p}<0.001)$. Strategies to increase walking for transportation or
\end{abstract}

(C) 2013 Elsevier Ltd. All rights reserved.

Correspondence To: Mary O. Hearst, Ph.D., M.P.H., St. Catherine University, 2004 Randolph Ave, St. Paul, MN 55105, 651-690-6157, mohearst@stkate.edu.

Publisher's Disclaimer: This is a PDF file of an unedited manuscript that has been accepted for publication. As a service to our customers we are providing this early version of the manuscript. The manuscript will undergo copyediting, typesetting, and review of the resulting proof before it is published in its final citable form. Please note that during the production process errors may be discovered which could affect the content, and all legal disclaimers that apply to the journal pertain. 
leisure need to take account of individual level socioeconomic factors in addition to area-level measures.

\section{Keywords}

Adult; walking; area deprivation; socioeconomic status; active transportation; policy

\section{Introduction}

Understanding walking patterns is important because overweight and obesity among adults in the United States is at critical levels. Two-thirds of U.S. adults are overweight and obese, with one-third in the obese category (Flegal, Carroll et al. 2012). There are many serious consequences to overweight and obesity, including heart disease, stroke, diabetes, cancer and early mortality (National Heart Lung and Blood Institute 1998). One important cause of obesity is inadequate levels of physical activity. The 2008 National Activity Guidelines for Americans recommend a minimum of 150 minutes of moderate-intensity physical activity per week (U.S. Department of Health and Human Services 2008). Despite this recommendation, $25 \%$ of adults in the US report no leisure-time physical activity (MMWR 2008). Walking is an important and accessible means of physical activity for many adults. An advantage of walking for physical activity is that it can serve a utilitarian purpose, such as walking for transportation. In fact, walking three times per day in 10 minute bursts of brisk walking, as may be typical of walking for transportation, can meet national daily physical activity recommendations (Centers for Disease Control and Prevention 2008).

In 2001, the National Household Travel Survey (NHTS) found that only 10\% of trips by adults were made wholly or partially on foot (Agrawal and Schimek 2007). While only about $2 \%$ of NHTS trips were on public transportation, adults who used public transportation spent a median of 19 minutes daily walking to and from transit stops, with an estimated 29\% achieving the recommended 30 minutes per day of physical activity through this means (Besser and Dannenberg 2005). In addition to health benefits (Centers for Disease Control and Prevention 2008), walking for transportation is often thought to reduce road congestion, support environmental conservation of fossil fuels and enhance 'liveability' within communities (Blanco, Alberti et al. 2009). Understanding what distinguishes walking behavior is of vital concern when designing transportation policies, plans, and programs to promote active travel.

Researchers and practitioners from both the health and transportation fields are also encouraging walking for transportation as a means of increasing physical activity. However, there is much that remains unknown about the determinants of non-motorized travel and the importance of individual characteristics, household characteristics or environmental factors associated with active transportation (Blanco, Alberti et al. 2009). It has been shown that the type of walking (transportation versus leisure) differs by individual income level with lower income individuals walking more as a form of transportation (Besser and Dannenberg 2005; Agrawal and Schimek 2007). Walking for transportation or utilitarian purposes tends to be higher in areas of higher density, mixed-use patterns and with pedestrian friendly design features while recreational walking features are correlated with large blocks and less mixeduse patterns (Saelens, Sallis et al. 2003; Forsyth, Oakes et al. 2007; Forsyth, Hearst et al. 2008; Saelens and Handy 2008). However, the research is somewhat mixed regarding individual characteristics of who walks and for what purpose in what type of neighborhood (Forsyth, Oakes et al. 2009b), suggesting that neighborhood context as well as individual characteristics may affect walking patterns. 
The purpose of this paper was to explore the role of the neighborhood sociodemographic context and patterns of walking behavior and the simultaneous relationship with household and individual level sociodemographic characteristics. We considered three kinds of walking among adults - total walking, transportation-related walking and leisure walking. We hypothesized, in accordance with theories from both transportation and public health, that associations between socioeconomics and walking observed at the area-level will be reduced by household and individual-level characteristics such as socioeconomic markers. That is, some of the apparent links found when looking at a person's neighborhood socioeconomic context and levels of walking, would be due to their individual characteristics. To our knowledge, while there has been a great deal of work on the neighborhood level built environment and walking in the public health literature, this is the first such paper to examine the relative effects of a complex, multi-dimensional, area deprivation measure and household and individual level-characteristics on adult walking patterns specifically aimed at the transportation field.

\section{Methods}

Data for this analysis came from two community-based studies of adolescent obesity that examined potential predictors of unhealthy weight gain in youth at multiple contextual levels including individual, home, school and neighborhood levels. These studies collected data from adolescents and a parent (or another adult caregiver.) This paper uses the sample of parents. The first study, the Transdisciplinary Research on Energetics and Cancer Centers-Identifying Determinants of Eating and Activity (TREC-IDEA) study recruited and adolescent and one parent and collected data in 2006-2007 from a preexisting cohort (Widome, Forster et al. 2007), a permit application listing from the Minnesota Department of Motor Vehicles, and a convenience sample from the St. Paul-Minneapolis metropolitan area (Lytle 2009).

The Etiology of Childhood Obesity (ECHO) study participants were recruited in 2007-2008 from the membership of the HealthPartners (HP) health plan within the 7-county metropolitan area of Minneapolis, St. Paul, Minnesota. The study used a recruitment procedure that targeted a range of overweight and healthy weight youth and parent members and that oversampled minorities.

The TREC-IDEA (2006-2007) and ECHO (2007-2008) studies used identical data collection instruments and a population from the same catchment area. The analysis for this paper used data from the parent survey, a parent physical activity questionnaire and participants' addresses matched to census tract information. Both studies were approved by the University of Minnesota Institutional Review Board.

\section{Calculations}

\subsection{Measures}

Leisure, transportation and total walking minutes per day were collected using the International Physical Activity Questionnaire (IPAQ) long form for the last seven days. The IPAQ is an internationally validated (Craig, Marshall et al. 2003; International Physical Activity Questionnaire Core Group 2005) questionnaire designed to capture physical activity among adults across four domains - leisure, transportation, work and household. Summary variables were calculated including total leisure minutes per day (LMD), transportation minutes per day(TRMD) and a summed score of total walking minutes per day (TMD)(International Physical Activity Questionnaire Core Group 2005). Although recall surveys have disadvantages in contrast with many travel diary studies, the IPAQ was an appropriate instrument for this study as it has the advantage of providing data covering 
seven days, and has demonstrated moderate correlations with accelerometer data in lowincome adult populations (Wolin, Heil et al. 2008). IPAQ questions about total walking are comparable to the 2001 National Household Transportation Survey that asks the number of times in the past week the respondent took "a walk outside including walks for exercise" (Agrawal and Schimek 2007). Test-retest Spearman correlation coefficients from a multicountry validation study indicated the IPAQ long form asking about a "usual week" had good reliability in the USA (Craig, Marshall et al. 2003).

Area Sociodemographic Environment (ASDE) at the census tract level was used as a proxy for neighborhood SES. The area deprivation index, here titled ASDE, was developed by Singh (2003) using factor analysis and is measured using a composite of seventeen 2000 U.S. census variables (www.census.gov). It is considered to approximate the material and social conditions and relative socioeconomic advantages or resources in a given community (Singh 2003). The dimensions include: education; employment status, unemployment; median income, poverty rates; area income disparity; home values, rent, home-ownership rates, and mortgage costs; single parent households; households without a motor vehicle or telephone; housing units without complete plumbing or with more than one person per room. Higher values represent a more challenging environment, or per Singh's definition, more deprivation. Participants' addresses were matched to census tracts and the dimensions described were extracted from the U.S. Census for the census tract where the participant lived. The reported Cronbach's alpha for this measure was 0.95, indicating a high degree of internal consistency (Singh 2003) High internal consistency is important because it reflects how well the items used to construct the ASDE are correlated and to what extent the items measure the same latent construct, in this case, the area-level sociodemographic environment (DeVellis 2003). The National range for the ASDE using the 1990 census was 70.27 (least deprived) to 160.32 (most deprived) (Singh 2003).

Household characteristics data were collected via a parent and child survey during the clinic visit. The child was asked to describe the household composition including options to define single versus dual-parent households. Parents reported their gender, age, race (recoded as white versus other), the number of hours worked per week and the presence of young children (number under age 10 years) in the home to represent time constraints and define household characteristics and dynamics. Household attributes including sociodemographic and structural characteristics have been shown as explanatory variables for travel-mode choice (Lee, Hickman et al. 2007).

Individual SES data were collected via a parent survey during the clinic visit. Parents reported their education level (recoded to at least college education versus less), and if their child received free or reduced cost lunch at school. Students are eligible for free or reduced cost lunch if the family income is less than 1.3 or 1.85 times, respectively, the Federal income poverty guidelines. This translates to an annual income of less than $\$ 29,965$ or $\$ 42,642$ for a family of four (Department of Agriculture 2009; U.S. Department of Health and Human Services 2012). Education and free/reduced lunch status were used as proxy measures for individual SES in this analysis.

\subsection{Analysis}

Walking variables were assessed for skewness. As transportation, leisure and total walking minutes per day were not normally distributed, a square root function was used to transform the variables and the resulting transformed variables were used in the correlation and regression models. Descriptive statistics and mean comparisons were calculated and Pearson's correlations coefficients were used to assess bivariate relationships. Generalized estimating equations were used to model the relationship between ASDE, as quartiles, and walking behavior. These analyses accounted for study (IDEA or ECHO), individual and 
household characteristics and individual-level SES. In addition, given the recruitment related clustering of adolescents at the school level, we chose a conservative approach and accounted for potential intraclass correlation at the school the adolescent attended. This approach, as opposed to clustering at the census tract level, better accounts for lack of independence between parents living in a defined neighborhood. Effect modification was assessed between ASDE and both college education and free or reduced lunch status. If the interaction was significant $(\mathrm{p}<0.05)$, the models were stratified by individual characteristics to assess the differing roles of an area-based measure by individual characteristics. All analyses were conducted using SAS v.9.1 of the SAS System for Windows. (SAS Institute Inc 2002-2003)

\section{Results}

The combined sample from ECHO and IDEA yielded 550 participants with complete data. The adult sample was $79 \%$ female, well educated (college degree $=67 \%$ ) and $11 \%$ of the children in the study received free or reduced cost lunch at school compared with $32 \%$ in the state in 2007-2008 (Statistics 2010). Households were largely dual-parent, one-third had young children and the majority of parents worked at least part time. Participants reported total walking minutes per day $(\mathrm{TMD}=89)$; total minutes per day of leisure walking $(\mathrm{LMD}=28)$; travel walking minutes per day (TRMD=22) with the balance of 39 minutes composed of walking for other purposes such as job-related walking.

Mean comparisons of walking behavior by type according to quartiles of ASDE, college education and free and reduced lunch status revealed significant mean differences in minutes of daily walking with those with the least resources doing the most walking overall (see Table 2). Those from the highest two levels of resources or least disadvantaged neighborhoods had fewer minutes of transportation walking as compared to those coming from the least resourced or most disadvantaged neighborhoods. There were no differences in leisure walking by neighborhood characteristics but for total walking, those respondents living in the most disadvantaged neighborhoods reported more total walking time as compared to those in the least disadvantaged. There were no significant differences in walking by education level although there was a trend for less leisure walking for individuals reporting at least a college education. Finally, those respondents who did not report qualifying for free or reduced lunch had fewer minutes of transportation walking as compared with those that did qualify for free or reduced lunch.

Pearson's correlation coefficients (see Table 3) reflect statistically significant and positive, although modest, correlations between ASDE walking for transportation $(\mathrm{r}=0.08)$ and total walking $(\mathrm{r}=0.06)$. Leisure walking and ASDE were significantly and negatively correlated $(\mathrm{r}=-0.13)$. ASDE was positively related to families receiving free or reduced cost lunch $(\mathrm{r}=0.32)$ and negatively associated with college education $(\mathrm{r}=-0.29)$ as was anticipated. Adults were more educated and fewer families received free or reduced cost lunch in areas with less disadvantage. Leisure walking patterns were significantly and negatively correlated with receiving free or reduced lunch and positively correlated with college education. Transportation walking and leisure walking only share $1 \%$ of the variance, indicating that there is no meaningful relationship between a person who walks for transportation purposes and their leisure walking patterns.

Table 4 presents the results from the multivariate regression stepwise models, adjusted for study and clustering by school of the participants' children to account for potential intraclass correlation (Murray 1998). With ASDE modeled in quartiles, compared to the least disadvantaged areas, adults living in the most disadvantaged areas engaged in more minutes per day of transportation walking $(\beta=0.74, \mathrm{SE}=0.46, \mathrm{p}<0.05)$. Compared to the least 
disadvantaged areas, adults who live in the second most disadvantaged quartiles of ASDE engage in significantly fewer minutes per day of leisure walking $(\beta=-1.08, \mathrm{SE}=0.37$, $\mathrm{P}<0.05$ ). The least advantaged neighborhoods engaged in more total minutes of walking compared to most advantaged neighborhoods. Model 2 presents the associations after adjusting for individual demographic and household characteristics related to time demands including adult gender, age, race, dual-parent household, presence of young children at home and hours worked per week. The associations between walking type and ASDE were somewhat reduced for both leisure and total walking and attenuated to null for transportation walking. Adding individual-level SES, measured by college education and receiving free and reduced cost lunch as proxy variables, the relationships that had been significantbetween ASDE, transportation and total walking-became non-significant, although a relationship remained with leisure walking.

Effect modification was assessed for the individual level sociodemographic characteristics and ASDE. There was no significant interaction between college education and ASDE; however, significant interactions $(\mathrm{p}<0.001)$ were present between ASDE and free or reduced lunch status for transportation and total walking. This means that the role that neighborhood socioeconomic status has on walking is different depending on individual financial resources, in this case measured by free or reduced lunch status.

Models were stratified by free or reduced lunch status to assess the relationship of the ASDE on transportation and total walking behavior, but within individual level sociodemographic categories, asking if the environment matters more for those with low income versus high income (see Table 5.) Of those who qualified for free or reduced lunch (lower income), those who lived in the least disadvantaged neighborhoods engaged in 7.7 minutes less transportation walking and 10.7 minutes less total walking per day compared to those living in the most disadvantaged neighborhoods $(\mathrm{p}<0.001)$. No other significant relationships were present.

\section{Discussion}

This analysis added to the existing research on the effect of area-level sociodemographic environment on walking behavior. We asked if there was something unique about area-level measures of the neighborhood context that influenced walking for transportation, leisure walking or total walking. We did find an area-level association between ASDE and walking behavior. In bivariate analysis and preliminary models, we found that the total number of daily minutes of transportation and total walking was higher in areas with high disadvantage. Somewhat unexpectedly, leisure walking was higher in second most disadvantaged neighborhood compared to most advantaged. That is, people living in lower income areas walked more by all types. This is somewhat contradictory as other studies have reported consistently that minutes of leisure walking was positively associated with higher individual-level income (Kruger, Ham et al. 2008) and higher transportation-related walking with lower individual-SES (Berrigan, Troiano et al. 2006).

From an area level perspective, some researchers suggest that this different pattern in walking behavior occurs because of the differences in material infrastructure and collective social functioning between lower and higher income areas (Macintyre, Ellaway et al. 2002; Cerin and Leslie 2008; Cerin, Leslie et al. 2009). For example, in U.S. middle and high income suburban areas with large blocks and low densities, people may find leisure walking attractive; and there may be social networks that support such walking. Alternatively, middle and high income suburban areas are often not designed for mixed-use and transportation-related walking, so residents cannot safely and easily access other destination such as work or shopping by walking. 
However, areas of lower resources or more disadvantage are often central city or older suburban, mixed-use areas with public transportation and pedestrian infrastructure designed for active transportation to destinations (Forsyth, Hearst et al. 2008). As Saelens and Handy (2008) found in a review of 29 studies published in 2005-2006, transportation walking was associated with density, destinations, and land use mix with less clear results for street pattern (Saelens and Handy 2008). Thus, areas of high disadvantage/low resources may have more physical supports for transportation walking as they exist in a high density area.

When the household and individual-level characteristics (adult gender, age, race, young children at home, working status, dual parent households) were added to the regression model, minimal change in the associations between walking behavior and ASDE was observed. Certainly, household composition and time-use patterns such as dual-income households, work hours, work locations, presence of young children and management of multiple errands affect household decisions on transportation via car or public modes (Lee, Hickman et al. 2007; Maat and Timmermans 2009). However, the household level factors did not substantially diminish area-level factors.

When we added the individual level SES-related variables of college education and free and reduced cost lunch status, there were no longer significant associations between ASDE and transportation or total walking and leisure walking was attenuated suggesting that the differences in walking behaviors seen by neighborhood characteristics was captured in the variance explained by individual characteristics of college education and income level of the family.

The reduction of significant associations when adding individual-level SES is likely due to heterogeneity within neighborhoods. The ASDE does not reflect the full range of people living in an area, but is an average score, meaning the ASDE does not reflect the income heterogeneity seen in neighborhoods (Ionnides 2004). The data for this analysis revealed such heterogeneity of individuals living in an area as there were families who qualified for free or reduced cost lunch in the least deprived, or most wealthy, neighborhoods. Area-level measures do not account for the economic necessity of walking for transportation for lower income people. Neither do they account for self-selection into neighborhoods based on individual preferences for a more 'walkable' neighborhood (Oakes 2004). Other research also suggests that individual sociodemographic characteristics outweigh the importance of area-level built environment characteristics on distinguishing individual-level outcomes (Bodea, Garrow et al. 2009). This problem makes it difficult to disentangle from the impact of area-level measures from low-income individuals on walking behavior.

Finally, we tested for effect modification and in fact found differences in the relationship between ASDE and walking behavior by those with free or reduced lunch status. Those who qualify for free or reduced lunch engage in less transportation and total walking if living in an area with more sociodemographic resources (more advantaged) compared to fewer sociodemographic resources. This brings us back to our discussion of other factors that the ASDE may represent. If in fact areas with more sociodemographic resources (middle to upper income area) represent suburban areas with large blocks and low densities, and subsequently were not designed for mixed-use and transportation-related walking, the impact on transportation (and transportation related and total walking) is greatest among those individuals with low-income. They may also have less transit access, again reducing walking.

Individual economic status contributed to the patterns of walking behavior. But, differences in walking patterns by individual economic status may merely reflect variation in a person's motivation for physical activity in general (Butler, Orpana et al. 2007). But, our data suggest 
those with lower incomes also have less total walking if transportation walking is not occurring (Forsyth, Oakes et al. 2009b). It is also plausible that transportation walking is related to much more complicated processes such as personal preferences, social environment, and design and destination features (Forsyth, Hearst et al. 2008), walking at work, and the management of household demands according to household types (Lee, Hickman et al. 2007).

It is important to note that the current sample differed somewhat from the national data (Agrawal and Schimek 2007). Our sample reported an average of 22 minutes per day in transportation-related walking. Compare this with the 2001 National Household Travel Survey where Americans average 3.8 travel and leisure walk trips per week at 16.4 minutes per trip or an average of 9 minutes per day in travel walking, with 35\% reporting no walk trips in the prior week. Our study, on average, was comprised of a well-educated, relatively homogenous middle class sample, yet we did have a sample that qualified for free or reduced lunch which is by definition low-income. As stated, the average higher walking patterns supports the physical activity literature that higher SES individuals tend to walk more on average than lower SES individuals (Eyler, Brownson et al. 2003). The sample was also comprised of a large suburban population who tend to walk more leisure minutes each day compared to travel walking (Wells and Yang 2008). Our range of the ASDE (44-156) was generally comparable to the range seen using National data (70-160)(Singh 2003); however, we acknowledge that the range within the quartiles in our data did, compared to the National data, reflect more wealthy neighborhoods.

There are several other limitations to this research. The sample was dominated by women who were mothers- to enroll as an adult one had to be a parent and more mothers than fathers participated. These are both factors that affect commuting and leisure choices (Crane 2007) although the implications for total, transportation, and leisure walking are unclear for the current study. A longitudinal study did find that leisure walking decreased for women upon the birth of children and did not recover until children got older, while men's leisure time minutes per day rebounded back to almost previous levels (Parker, unpublished). Also, the ASDE was based on home address only and does not include other neighborhood exposures (work or between work and home) for leisure walking behavior (Meriwether, McMahon et al. 2006). This study examined the socioeconomic environment; further work could add built environment variables which were unfortunately not available at the same scale as the ADSE data. The survey did not ask about car access or transit use, questions that would be helpful in future studies. Finally, the IPAQ likely overestimated walking behavior but it is not clear what kind of bias, if any, this would introduce. This challenge of overestimation in physical activity measurement is well known in public health research. Still, the IPAQ has demonstrated acceptable measurement properties for assessing adult physical activity (Craig, Marshall et al. 2003).

\section{Conclusions}

The effect of area-level sociodemographic environment on walking behavior was dramatically reduced when individual SES was considered; however a significant interaction revealed that low-income individuals engage in fewer minutes of transportation-related and total walking if they live in areas that has low disadvantage/higher levels of resources, compared with those who live in areas with more disadvantage. Transportation and public health professionals have been interested in promoting walking as a common form of physical activity that is 'easy' to do and can potentially be increased and has environmental advantages. Currently many interventions focus on environmental change and education (Forsyth, Krizek et al. 2009a), however, this research demonstrates that strategies to increase walking for transportation or leisure need to take account of individual level socioeconomic 
factors in addition to area-level measures. These results certainly suggest the need for ubiquitous pedestrian infrastructure and public transportation options for areas that are economically disadvantaged and those that are not. If cities use planning policies to offer options to drive less and use non-motorized modes more, many residents will do so (Cao, Mokhtarian et al. 2009). In looking for the reasons people walk, household composition accounts for some variation, but individual level socioeconomic factors are very important points of leverage and should inform policy interventions and guide transportation professionals to find ways to promote walking that may be targeted differently at different groups. Policies can ensure walking infrastructure target all people -those that walk for leisure and transportation and from a health and environment perspective.

\section{Acknowledgments}

We would like to thank all the participants and study staff, including data collectors, data managers and other team members, for their contributions to this study and the funders for this research- grant number R01HL085978 from the National Heart, Lung, and Blood Institute and grant 1U54CA116849-01 from National Cancer Institute.

\section{References}

Agrawal A, Schimek P. Extent and Correlates of Walking in the USA. Transportation Research. 2007; 12(Part D):548-563.

Berrigan D, Troiano RP, et al. Active Transportation Increases Adherence to Activity Recommendations. American Journal of Preventive Medicine. 2006; 31(3):210-216. [PubMed: 16905031]

Besser LM, Dannenberg AL. Walking to public transit: steps to help meet physical activity recommendations. Am J Prev Med. 2005; 29(4):273-80. [PubMed: 16242589]

Blanco H, Alberti M, et al. Hot, congested, crowded and diverse: Emerging research agendas in planning. Progress in Planning. 2009; 71(4):153-205.

Bodea T, Garrow L, et al. Socio-demographic and built environment influences on the odds of being overweight or obese: The Atlanta experience. Transportation Research Part A: Policy and Practice. 2009; 44(7):523-536.

Butler G, Orpana H, et al. By Your Own Two Feet. Canadian Journal of Public Health. 2007; 98(4): 259-264.

Cao X, Mokhtarian P, et al. The relationship between the built environment and nonwork travel: A case study of Northern California. Transportation Research Part A: Policy and Practice. 2009; 43(5):548-559.

Centers for Disease Control and Prevention. 2008 Physical Activity Guidelines for Americans. 2008 Dec 17. Retrieved August 5, 2009, from http://www.cdc.gov/physicalactivity/everyone/guidelines/ adults.html

Centers for Disease Control and Prevention. Physical Activity and Health: The Benefits of Physical Activity. 2008 Aug 5. Retrieved August 5, 2009, from http://www.cdc.gov/physicalactivity/ everyone/health/index.html

Cerin E, Leslie E. How socio-economic status contributes to participation in leisure-time physical activity. Soc Sci Med. 2008; 66(12):2596-609. [PubMed: 18359137]

Cerin E, Leslie E, et al. Explaining socio-economic status differences in walking for transport: An ecological analysis of individual, social and environmental factors. Social Science \& Medicine. 2009; 68(6):1013-1020. [PubMed: 19193480]

Craig CL, Marshall AL, et al. International physical activity questionnaire: 12-country reliability and validity. Med Sci Sports Exerc. 2003; 35(8):1381-95. [PubMed: 12900694]

Craig CL, Marshall AL, et al. International Physical Activity Questionnaire: 12-Country Reliability and Validity. Medicine \& Science in Sports \& Exercise. 2003; 35(8):1381-1395. [PubMed: 12900694]

Crane R. Is there a quiet revolution in women's travel? Revisiting the gender gap in commuting. Journal of the American Planning Association. 2007; 73(3):298-316. 
Department of Agriculture. School Meals: Income Eligibility Guidelines. 2009. from Available from: http://www.fns.usda.gov/cnd/Governance/notices/iegs/IEGs.htm

DeVellis, R. Scale Development: Theory and Application. Thousand Oaks, CA: Sage Publications; 2003.

Eyler AA, Brownson RC, et al. The epidemiology of walking for physical activity in the United States. Med Sci Sports Exerc. 2003; 35(9):1529-36. [PubMed: 12972873]

Flegal KM, Carroll MD, et al. Prevalence of obesity and trends in the distribution of body mass index among US adults, 1999-2010. JAMA. 2012; 307(5):491-7. [PubMed: 22253363]

Forsyth A, Hearst M, et al. Design and Destinations: Factors Influencing Walking and Total Physical Activity. Urban Stud. 2008; 45(9):1973-1996.

Forsyth A, Krizek K, et al. Non-motorised travel research and contemporary planning initiatives. Progress in Planning. 2009a; 71:153-205.

Forsyth A, Oakes J, et al. Does Residential Density Increase Walking and Other Physical Activity. Urban Studies. 2007; 44(4):679-697.

Forsyth A, Oakes JM, et al. The built environment, walking, and physical activity: Is the environment more important to some people than others? Transportation Research Part D: Transport and Environment. 2009b; 14(1):42-49.

International Physical Activity Questionnaire Core Group. Guidelines for the data processing and analysis of the International Physical Activity Questionnaire. 2005

Ionnides Y. Neighborhood Income Distributions. Journal of Urban Economics. 2004; 56:435-457.

Kruger J, Ham SA, et al. Prevalence of transportation and leisure walking among U.S. adults. Prev Med. 2008; 47(3):329-34. [PubMed: 18445507]

Lee Y, Hickman M, et al. Household type and structure, time-use pattern, and trip-chaining behavior. Transportation Research Part A: Policy and Practice. 2007; 41:1004-1020.

Lytle LA. Examining the etiology of childhood obesity: The IDEA study. Am J Community Psychol. 2009; 44(3-4):338-49. [PubMed: 19838791]

Maat K, Timmermans H. Influence of the residential and work environment on car use in dual-earner households. Transportation Research Part A: Policy and Practice. 2009; 43:654-664.

Macintyre S, Ellaway A, et al. Place effects on health: how can we conceptualise, operationalise and measure them? Soc Sci Med. 2002; 55(1):125-39. [PubMed: 12137182]

Meriwether RA, McMahon PM, et al. Physical activity assessment: validation of a clinical assessment tool. Am J Prev Med. 2006; 31(6):484-91. [PubMed: 17169709]

MMWR. Prevalence of Self-Reported Physically Active Adults - United States, 2007. 2008; 57(48): 1297-1300.

Murray, D. Design and Analysis of Group-Randomized Trials. New York, NY: Oxford University Press; 1998.

National Heart Lung and Blood Institute. Obesity Eduction Initiative. Bethesda, MD: National Institutes of Health; 1998. Clinical Guidelines on the Identification, Evaluation, and Treatment of Overweight and Obesity in Adults.

Oakes JM. The (mis)estimation of neighborhood effects: causal inference for a practicable social epidemiology. Soc Sci Med. 2004; 58(10):1929-52. [PubMed: 15020009]

Saelens BE, Handy SL. Built environment correlates of walking: a review. Med Sci Sports Exerc. 2008; 40(7 Suppl):S550-66. [PubMed: 18562973]

Saelens BE, Sallis JF, et al. Environmental correlates of walking and cycling: findings from the transportation, urban design, and planning literatures. Ann Behav Med. 2003; 25(2):80-91. [PubMed: 12704009]

SAS Institute Inc. SAS/STAT. SAS Institute Inc; Cary, NC: 2002-2003.

Singh GK. Area deprivation and widening inequalities in US mortality, 1969-1998. Am J Public Health. 2003; 93(7):1137-43. [PubMed: 12835199]

Statistics, N. C. f. E. State Data Profiles, Minnesota. 2010

U.S. Department of Health and Human Services. 2008 Physical Activity Guidelines for Americans. 2008. Retrieved November 18, 2008, from http://www.health.gov/PAguidelines/pdf/paguide.pdf 
U.S. Department of Health and Human Services. 2012 HHS Poverty Guidelines. 2012 Feb 9. Retrieved August 10, 2012, from http://aspe.hhs.gov/poverty/12poverty.shtml/\#thresholds

Wells NM, Yang Y. Neighborhood design and walking. A quasi-experimental longitudinal study. Am J Prev Med. 2008; 34(4):313-9. [PubMed: 18374245]

Widome R, Forster JL, et al. Longitudinal patterns of youth access to cigarettes and smoking progression: Minnesota Adolescent Community Cohort (MACC) study (2000-2003). Prev Med. 2007; 45(6):442-6. [PubMed: 17719080]

Wolin KY, Heil DP, et al. Validation of the International Physical Activity Questionnaire-Short among Blacks. J Phys Act Health. 2008; 5(5):746-60. [PubMed: 18820348] 


\section{Research Highlights}

- The effect of area-level SES on adult walking behavior disappeared when individual SES was considered.

- There is a need for ubiquitous pedestrian infrastructure and public transportation options.

- Individual level socioeconomic factors can inform policy and guide transportation professionals to promote walking. 


\section{Table 1}

Sample characteristics by variables of interest $(n=550)$

\begin{tabular}{|c|c|c|c|c|c|}
\hline & & $\%$ & & & \\
\hline Female & & 78.6 & & & \\
\hline Dual-headed Household & & 81.1 & & & \\
\hline College educated & & 66.7 & & & \\
\hline White & & 94.0 & & & \\
\hline Dual-parent households & & 82.1 & & & \\
\hline \multirow[t]{6}{*}{ Hours worked } & Not employed & 13.6 & & & \\
\hline & $<10$ hours per week & 4.0 & & & \\
\hline & $10-20$ hours per week & 8.4 & & & \\
\hline & $21-40$ hours per week & 35.3 & & & \\
\hline & 41-50 hours per week & 30.4 & & & \\
\hline & $>50$ hours per week & 8.4 & & & \\
\hline Child receives FRL at school & & 10.6 & & & \\
\hline Children $0-10$ years at home & & 33.6 & & & \\
\hline \multirow[t]{5}{*}{ Area Sociodemographic Environment } & Most resources (1) & 27.1 & & & \\
\hline & 2 & 23.8 & & & \\
\hline & 3 & 26.6 & & & \\
\hline & Least resources (4) & 22.6 & & & \\
\hline & & Mean & SD & Min & Max \\
\hline Age & & 45.9 & 5.7 & 26.0 & 70.0 \\
\hline Area Sociodemographic Environment & & 82.2 & 17.7 & 43.6 & 156.7 \\
\hline \multirow[t]{4}{*}{ Area Sociodemographic Environment } & Most resources (1) & 64.8 & 5.1 & 43.6 & 72.5 \\
\hline & 2 & 76.3 & 2.0 & 72.5 & 79.7 \\
\hline & 3 & 85.2 & 3.6 & 79.7 & 91.5 \\
\hline & Least resources (4) & 109.4 & 16.6 & 91.6 & 156.7 \\
\hline \multicolumn{6}{|l|}{ Walking behavior 1} \\
\hline Transportation & & 22.4 & 41.7 & 0 & 420 \\
\hline Leisure & & 27.8 & 37.7 & 0 & 420 \\
\hline Total & & 88.6 & 96.6 & 0 & 510 \\
\hline
\end{tabular}

${ }^{1}$ Minutes of walking type per day 


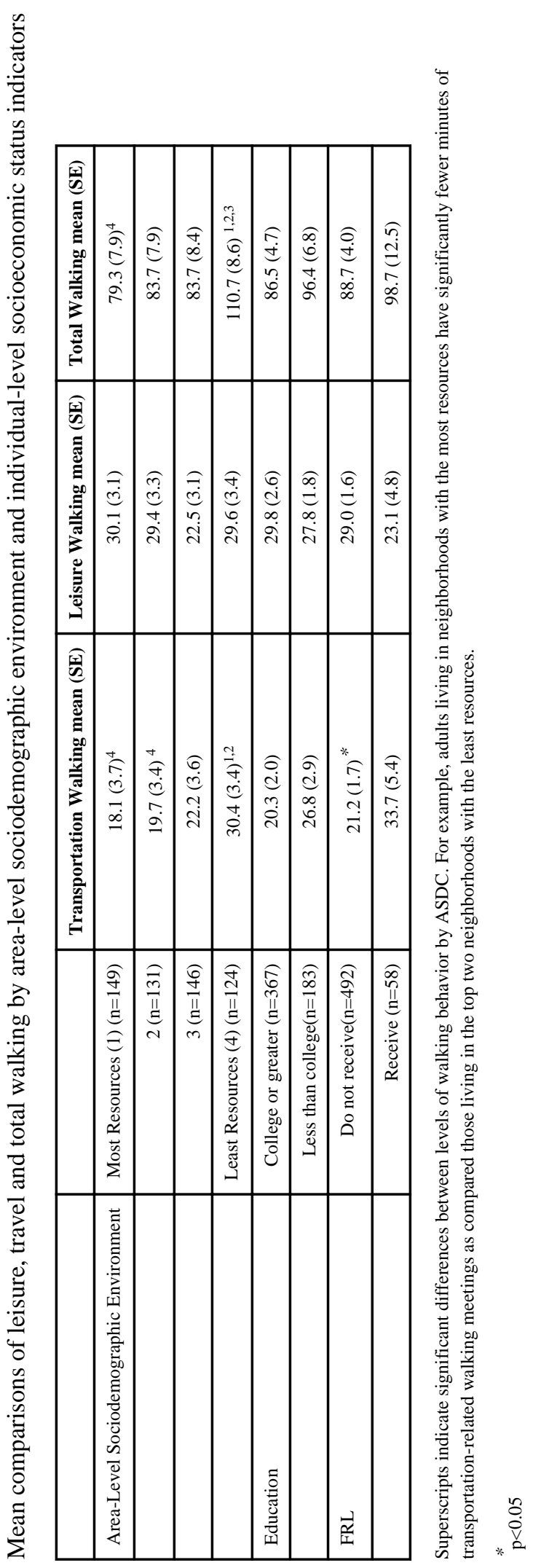

Transp Res Part A Policy Pract. Author manuscript; available in PMC 2014 April 01. 


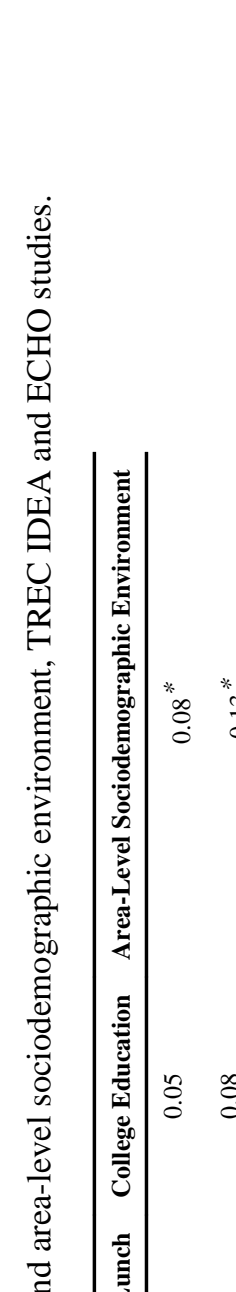

후

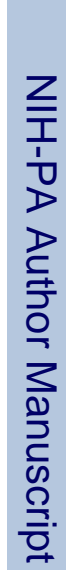

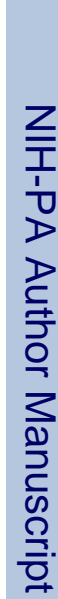

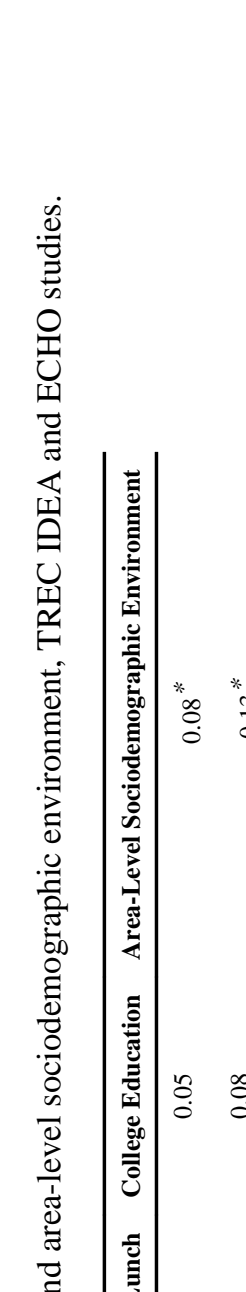

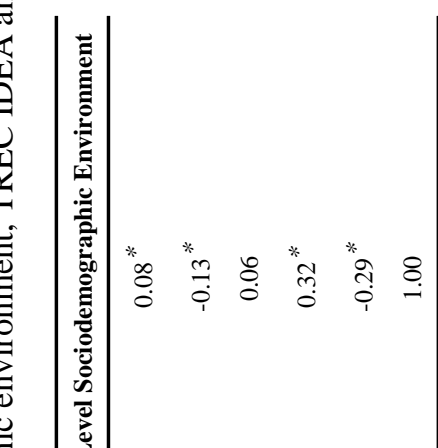

告

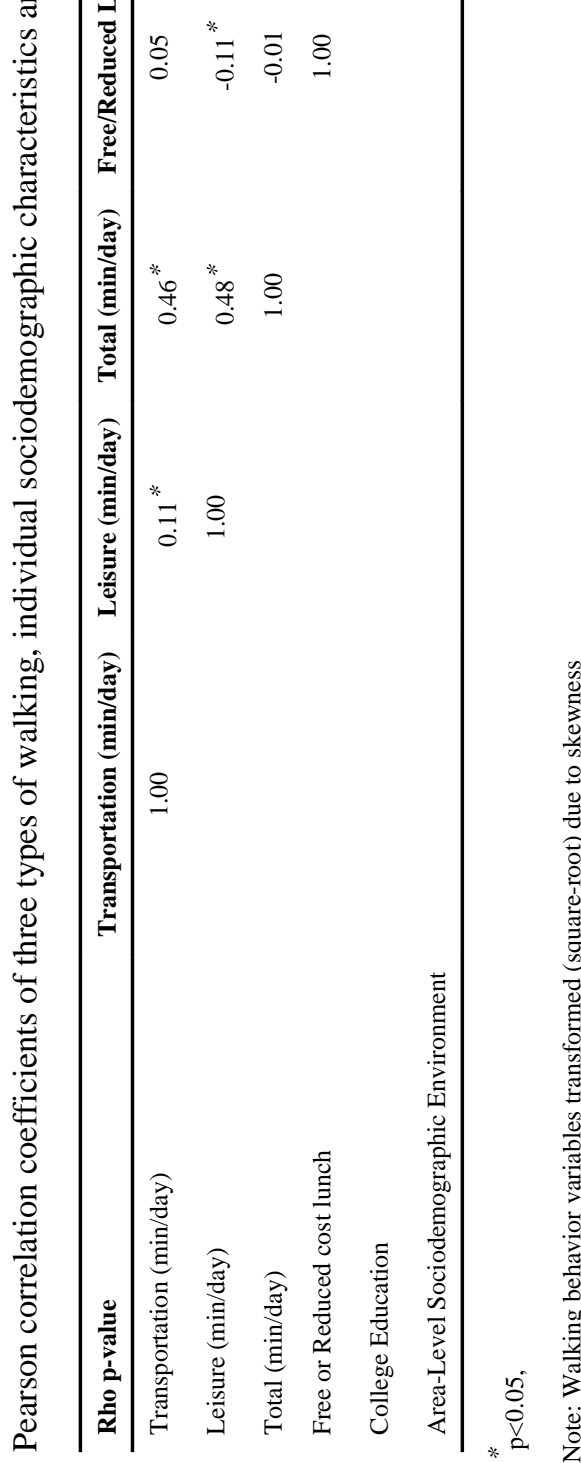

Transp Res Part A Policy Pract. Author manuscript; available in PMC 2014 April 01. 


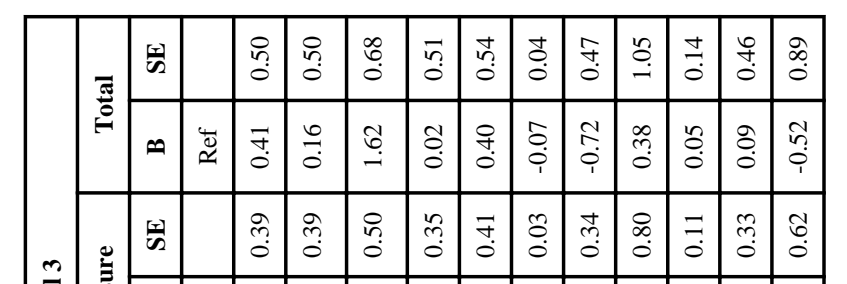

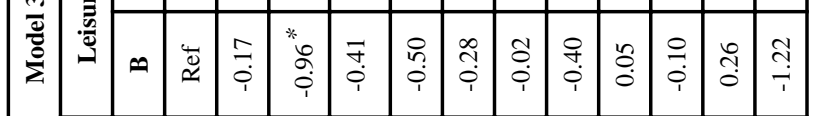

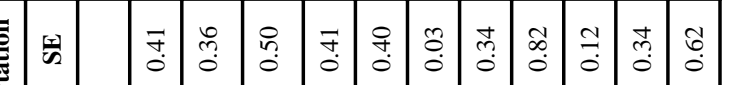

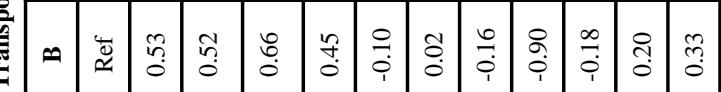

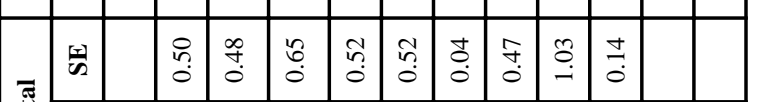

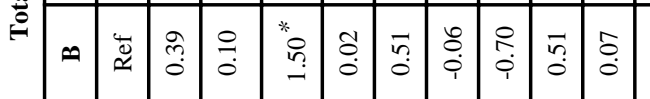

$\div$ ฯ

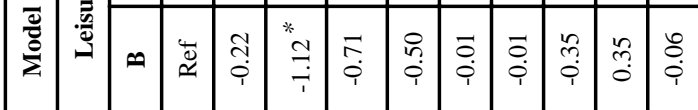

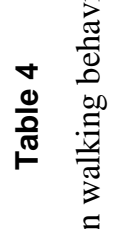

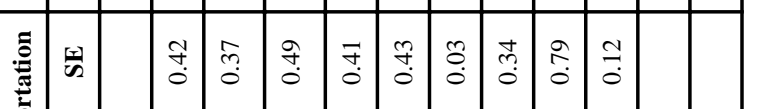

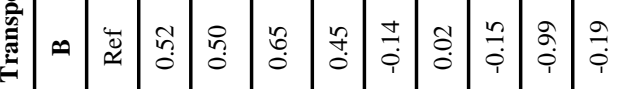

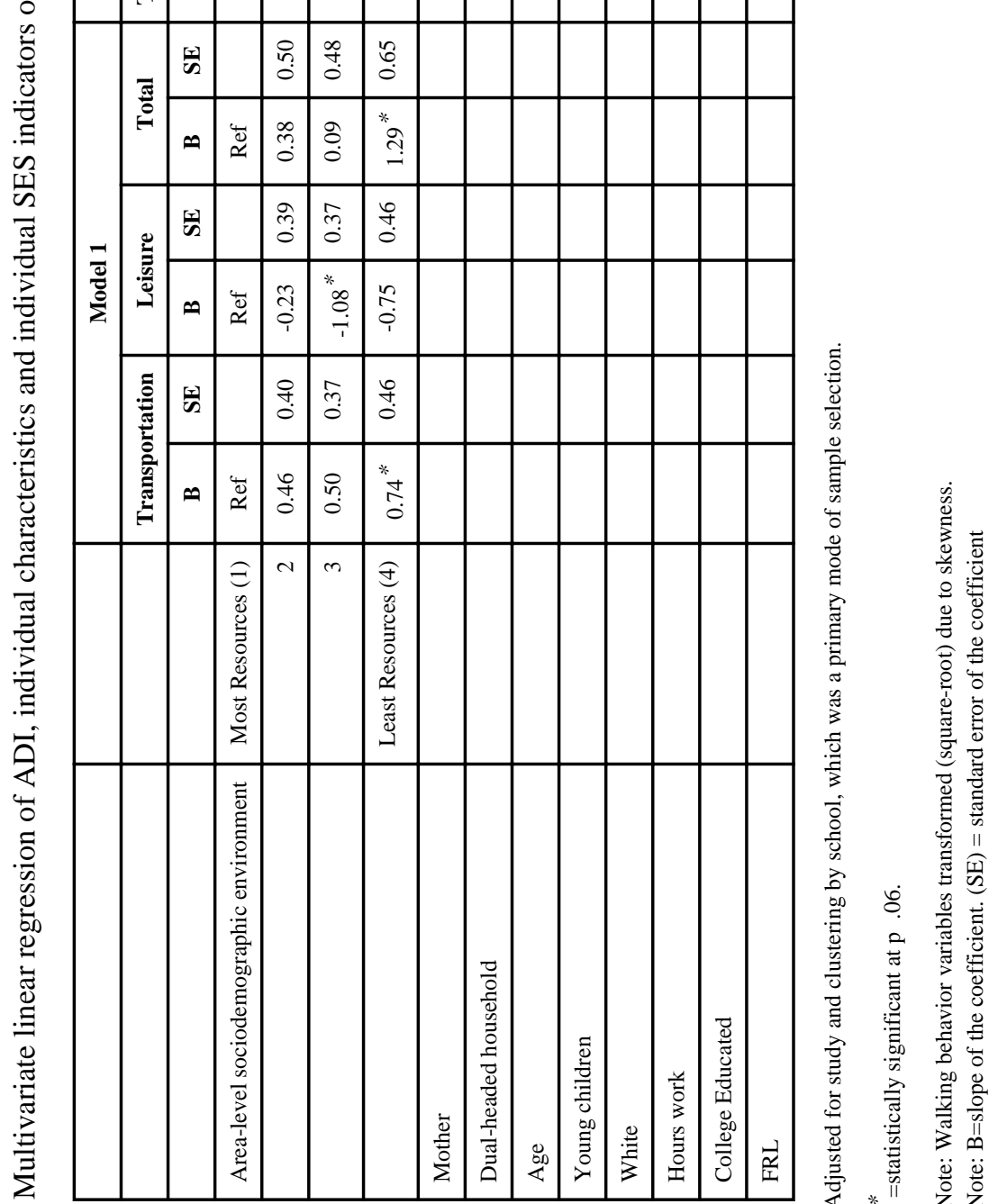




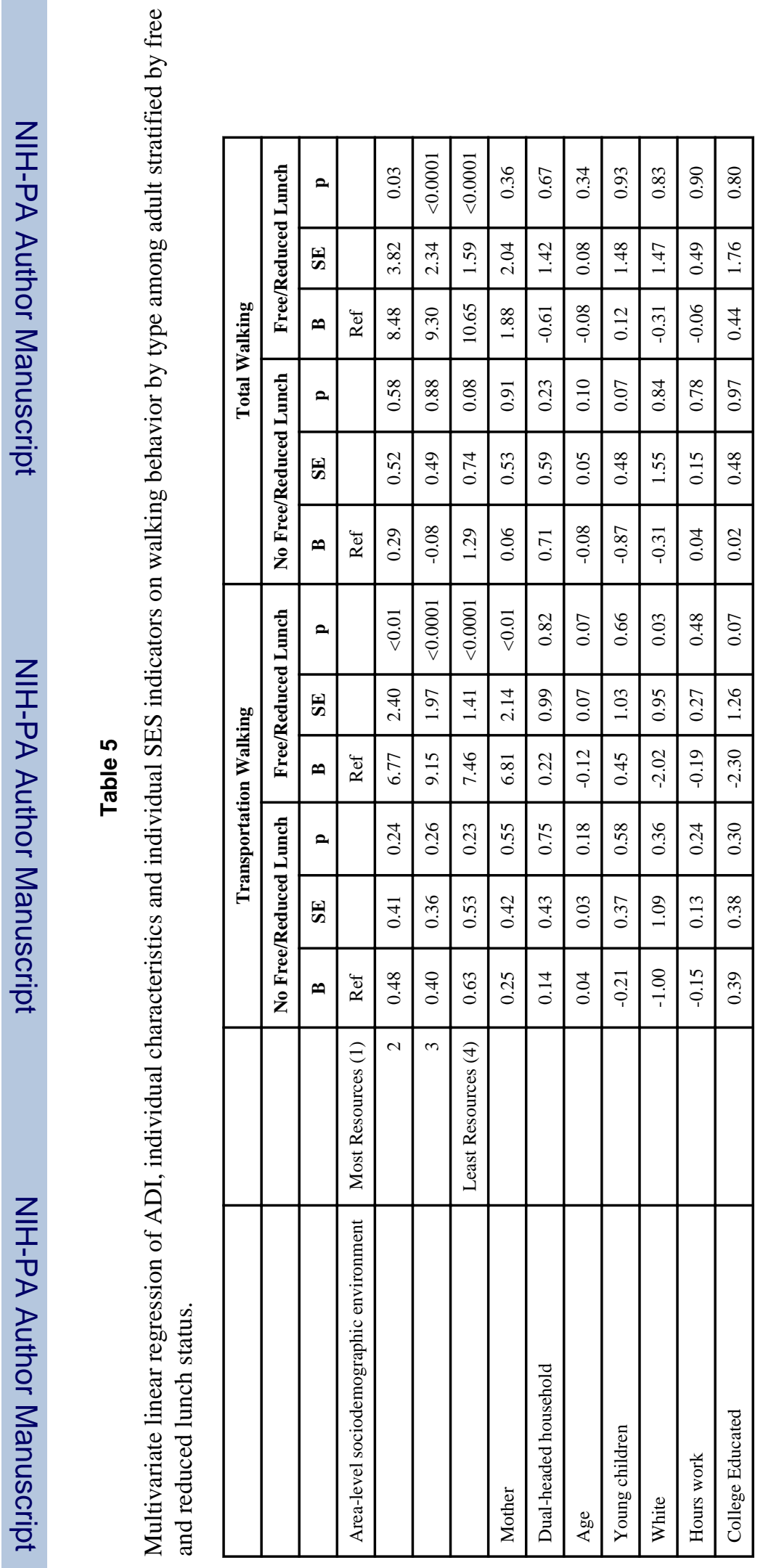

